\title{
Ventricular Fibrillation in a Tetraplegic Patient who had a Therapeutic Level of a Tricyclic Antidepressant Case Report
}

\author{
Randy Levin, ^ M.D., Douglas M. Burtt, M.D., William A. Levin, M.D. \\ and Michael B. Ginsberg, M.D. \\ Department of Medicine, the Divisions of Neurology, Cardiology and Infectious \\ Diseases, Brown University and Roger Williams General Hospital, 825 Chalkstone \\ Avenue, Providence, Rhode Island, U.S.A.
}

\section{Summary}

A case is presented of a young, chronic tetraplegic patient who, shortly after achieving therapeutic levels of imipramine, a tricyclic antidepressant (TCA) developed a life-threatening ventricular arrhythmia. Since tetraplegic patients frequently manifest evidence of autonomic supersensitivity, the autonomic effects of the TCA may have led to the cardiac arrhythmia. Caution should be exercised in the use of TCA's in tetraplegic patients.

Key words: Tetraplegia; Tricyclic antidepressants; Ventricular fibrillation.

\section{Introduction}

Tricyclic antidepressants (TCA) are the most widely used medication in the treatment of depression. Over the last 15 years, the toxic effects of these drugs have been extensively reported (Preskorn and Irwin, 1982), and, more recently, the cardiovascular effects of these drugs at therapeutic doses for depression have been documented (Glassman and Bigger, 1981).

A significant number of chronic tetraplegics are treated for depression with TCAs. Such patients are very sensitive to stimuli that disrupt autonomic homeostasis as a result of blockade of autonomic outflow from the hypothalamus to autonomic end organs (Erickson, 1980). We present the case of a chronic tetraplegic patient who developed life-threatening ventricular arrhythmias shortly after achieving therapeutic serum levels of TCAs.

\section{Case report}

A 25-year-old male tetraplegic patient was admitted to hospital with palpitations.

Address for reprints: Michael B. Ginsberg, M.D., Assistant Professor of Medicine, Brown University Program in Medicine, Roger Williams General Hospital, 825 Chalkstone Avenue, Providence, RI 02908.

*Currently with the Department of Neurology at the University of Virginia Hospitals, Charlottesville, Virginia. 
The patient had suffered a spinal cord injury at age 18 years resulting in a complete sensory and motor deficit below C6. Three weeks prior to admission, he was started on imipramine for agitated depression and the dose was slowly increased over a 2 -week period to $200 \mathrm{mg}$ PO q hs. On the day of admission, the patient complained of palpitations, nervousness, a 'flushed feeling', dry mouth, urinary retention, confusion, and drowsiness. His imipramine was discontinued and the patient was admitted to hospital. Medications included diazepam $5 \mathrm{mg}$ PO q.i.d. PRN, and dantrolene sodium $50 \mathrm{mg}$ PO t.i.d., both of which he had been taking for many years. The patient denied other drug ingestion, alcohol consumption, fever, chills, change in bowel habits, history of previous palpitations, cardiac disorders including rheumatic heart disease and cardiac murmur or family history for cardiac disease.

Physical examination revealed an anxious and restless white male patient with a pulse of $160 /$ minute and regular, a blood pressure of $140 / 90$, a respiratory rate of 32 , and a rectal temperature of $37.8^{\circ} \mathrm{C}$. The skin was flushed, warm and dry, without lesions. The head and neck examination was notable only for slightly dilated ( $5 \mathrm{~mm})$, but normally reactive pupils. The lungs were clear. Examination of the heart revealed a rapid, regular rate; no rubs, murmurs or gallops were heard. The neurological examination was unchanged from previous examinations, and revealed a sensory and motor level at C6. The patient was unable to void urine, therefore a catheter was placed in the bladder and $500 \mathrm{cc}$ of urine was drained, without change in his vital signs.

Laboratory data revealed a WBC count of 16,700 with a normal differential. The haemoglobin, haematocrit, glucose, BUN, creatinine, and serum electrolytes were all within normal limits. Cardiac isoenzymes were not detected. A blood and urine toxicology screen was positive only for a therapeutic desipramine (an active breakdown product of imipramine) level of $0.1 \mathrm{mcg} / \mathrm{ml}$. A chest X-ray, an impedance plethysmogram, and an echocardiogram were normal. The EKG revealed sinus tachycardia (rate 150), with a normal $\mathrm{QT}_{\mathrm{c}}$ interval; a rhythm strip demonstrated occasional unifocal ventricular premature beats. Several urine, blood and sputum cultures showed no significant growth. An arterial blood gas on room air revealed a $\mathrm{pH} 7.61, \mathrm{pCO}_{2} 18, \mathrm{pO}_{2} 107$.

The patient remained haemodynamically stable for 3 hours. He then spontaneously developed ventricular tachycardia which rapidly degenerated to ventricular fibrillation. The patient was electrically defibrillated with 200 joules to sinus tachycardia, received 2 bolus I.V. injections of lidocaine $50 \mathrm{mg}$ and was maintained on I.V. lidocaine at $2 \mathrm{mg} / \mathrm{min}$. Post-resuscitation, the patient was hypotensive requiring a dopamine infusion to maintain a systolic blood pressure of $90 \mathrm{mmHg}$. A Swan-Ganz catheter and an arterial line were inserted. The pulmonary capillary wedge pressure was $20 \mathrm{mmHg}$. The cardiac index was $2.81 / \mathrm{min} / \mathrm{m}^{2}$ (normal $2.5 \mathrm{l} / \mathrm{min} / \mathrm{m}^{2}$ ). The calculated peripheral vascular resistance was 940 units, within normal limits.

On the second and third hospital days, the desipramine levels were 0.05 $\mathrm{mcg} / \mathrm{ml}$ and $0.04 \mathrm{mcg} / \mathrm{ml}$, respectively. The dopamine infusion was slowly tapered and then discontinued on the fourth hospital day. The lidocaine was also discontinued on that day without recurrence of any ventricular ectopy. The pulse gradually slowed to $90 /$ min over 4 days. The predischarge EKG was within normal limits. The patient was discharged on the fifteenth hospital day and has remained without further symptoms for 1 year. 


\section{Discussion}

TCA's interfere with autonomic neurotransmission by at least three mechanisms: peripheral and central anticholinergic action; blockade of the re-uptake of norepinephrine (Hollister, 1978); and central and peripheral alpha-adrenergic blockade (U'Prichard et al., 1978). Tetraplegics, with their autonomic receptor supersensitivity, could have an exaggerated response to these disruptive mechanisms.

TCA's are well known to cause ventricular arrhythmias in patients with supratherapeutic levels. There are also scattered reports in the literature of ventricular arrhythmias at therapeutic levels in patients with cardiac disease (Marshall and Faeker, 1982), but this evidence is controversial (Giardina et al., 1970). Also controversial is the interpretation of plasma TCA levels. While some state that the plasma TCA level correlates well with tissue concentration (Preskorn and Irwin, 1982), other studies have shown that tissue levels, which are highest in cardiac muscle, can be ten times higher than plasma levels (Hollister, 1978).

The major mechanism postulated for TCA induced ventricular arrhythmias involves the blockade of the re-uptake of norepinephrine at the cell membrane. This leads to increased levels of norepinephrine and potentiation of neuronal activity which could produce arrhythmias by activating latent pacemaker cells (Thorstrand, 1975). In tetraplegic patients, sympathetic decentralisation leads to an increase in the responsiveness of cells to norepinephrine due to an increase in the number and/or efficiency of receptors (Mathias, 1976). In combination with the effect of norepinephrine re-uptake blockade, this heightened sensitivity known to exist in tetraplegic patients could lead to the production of ventricular arrhythmias even at therapeutic levels of TCA.

The case described and the mechanisms proposed suggest that life-threatening complications can occur in tetraplegic patients receiving standard doses of TCA. More investigation of the cardiovascular and autonomic consequences of TCA therapy is needed to assure safety in the use of these drugs in the tetraplegic patient.

\section{Résumé}

Nous presentons le cas d'un jeune malade avec tetraplegie chronique qui tout de suite aprés avoir atteint un niveau therapeutique de l'antidepressant Tricyclique (imipramine), a developé une arrythmie ventriculaire dangereuse. Reconaissant que les tetraplegiques peuvent montrer une supersensitivité autonomique, l'effet du medicament peut être á l'origine de l'arrythmie cardiaque. Prudence est necessaire avec l'usage des antidepressants Tricyclique chez les tetraplegiques.

\section{Zusammenfassung}

Der Fall eines jungen tetraplegischen Patienten ist dargestellt, welcher kurz nach Erreichung einer therapeutischen Conzentration von Imipramin, ein trizyklisches Antidepressivum (TZA), eine lebensbedrohende ventrikuläre Arrhythmie entwickelte. Da Tetraplegen offenbar häufig Zeichen von autonomer Reizüberempfindlichkeit zeigen, möge die Wirkung von TZA zur Pulsarrhytmie geführt haben. Vorsicht soll geübt werden im Gebrauch von TZA an Tetraplegen.

\section{References}

PrESKORN SH, IRWIN HA 1982 Toxicity of tricyclic antidepressants-kinetics, mechanism, 
intervention: a review. J Clin Psychiatry, 43:151-6.

Glassman AH, Bigger JT 1981 Cardiovascular effects of therapeutic doses of tricyclic antidepressants. A review. Arch Gen Psychiatry 38:815-20.

ERICKSON RP 1980 Autonomic hyperreflexia: pathophysiology and medical management. Arch Phys Med Rehabil, 60:431-440.

Hollister LE 1978 Tricyclic antidepressants. NEJM, 299:1106-1109.

U'Prichard DC, GReEnberg DA, Sheehan PP, SNYder SH 1978 Tricyclic antidepressants: therapeutic properties and affinity for noradrenergic receptor binding sites in the brain. Science, 199:197-9.

MARShall JB, ForkeR AD 1982 Cardiovascular effects of tricyclic antidepressant drugs: therapeutic usage, overdose and management of complications. Am Heart J, 103:401-414.

Giardina E-GV, Bigger JT, Glassman AH, Penel JM, Kantor SJ 1979 The electrocardiographic and antiarrhythmic effects of imipramine hydrochloride at therapeutic plasma concentrations. Circulation, 60:1045-1052.

THORSTRAND C 1975 Cardiovascular effects of poisoning by hypnotic and tricyclic antidepressant drugs. Acta Med Scan (Suppl), 583:1-34.

Mathias CJ, Frankel HL, Christensen NS, Spalding JMK 1976 Enhanced pressor response to noradrenaline in patients with cervical spinal cord transsection. Brain, 99:757-770. 